\title{
EFFECT OF STRAIN ACCUMULATION UNDER HIGH TEMPERATURE THERMOMECHANICAL PROCESSING ON THE ROLLING FORCE AND MECHANICAL PROPERTIES OF AUSTENITIC STAINLESS STEEL WITH VARIOUS CARBON CONTENT
}

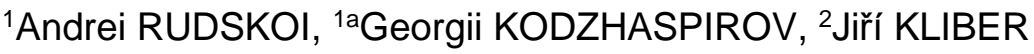 \\ ${ }^{1}$ Peter the Great St.Petersburg Polytechnic University, 195251, St.Petersburg, Russia, \\ agkodzhaspirov@gmail.com \\ ${ }^{2}$ VSB - Technical University of Ostrava, Ostrava, Czech Republic, EU
}

https://doi.org/10.37904/metal.2020.3468

\begin{abstract}
The effect of the strain accumulation by changing the number of rolling passes on the rolling force, structure and mechanical properties of austenitic $\mathrm{Cr}-\mathrm{Ni}$-Ti stainless steel with different carbon contents has been studied. An increase of the number of passes for a given overall reduction was found to have a beneficial effect on tensile properties while maintaining adequate ductility. At a rolling temperature of $1100-1150{ }^{\circ} \mathrm{C}$ with rolling in 1-3 passes, an increase in carbon content leads to acceleration of softening processes. With a lower rolling temperature and an increased number of passes, the reverse effect is obtained. When working out rolling schedules for sequences in HTMP conditions involving cooling before the final passes, residual hardening must be taken into account in rolling force calculations to prevent to prevent the mechanical equipment of the rolling stand from the breakage.
\end{abstract}

Keywords: Thermomechanical Processing (TMP), rolling pressure, austenitic stainless steel, mechanical properties

\section{INTRODUCTION}

When the fractional multi-pass hot rolling of steels it is important to take into account of the residual strengthening, which can increase from one pass to the next one. Investigations on High-Temperature Thermomechanical Processing (HTMP) of austenitic-type steels with titanium during single-pass rolling showed that this steel tends to soften very little, so as such steel with fcc lattice has a low stacking fault energy and correspondingly and correspondingly it is not inclined to fast static recrystallization $[1,2]$.

\section{EXPERIMENTAL PROCEDURE}

In the present work, it was studied the effect of the number of passes on the rolling pressure, mechanical properties, and structure of $\mathrm{Cr} 18-\mathrm{Ni9}-\mathrm{Ti}$ steel with different carbon contents.

The steels chemical compositions presented in Table 1.

Table 1 Chemical composition of steels, \% wt.

\begin{tabular}{|c|c|c|c|c|c|c|c|c|}
\hline Steel & C & Si & Mn & $\mathrm{Cr}$ & $\mathrm{Ni}$ & Ti & $\mathbf{S}$ & $\mathbf{P}$ \\
\hline 0.04C18Cr9NiTi & 0.04 & 0.6 & 1.1 & 17.9 & 9.1 & 0.21 & 0.014 & 0.003 \\
\hline $0.1 \mathrm{C} 18 \mathrm{Cr} 9 \mathrm{NiTi}$ & 0.10 & 0.7 & 1.1 & 17.9 & 8.8 & 0.56 & 0.012 & 0.012 \\
\hline $0.15 \mathrm{C} 18 \mathrm{Cr} 9 \mathrm{NiTi}$ & 0.15 & 0.7 & 1.1 & 18.3 & 9.0 & 0.75 & 0.012 & 0.014 \\
\hline $0.2 \mathrm{C} 18 \mathrm{Cr} 9 \mathrm{NiTi}$ & 0.2 & 0.6 & 1.15 & 18.1 & 9.0 & 0.40 & 0.014 & 0.008 \\
\hline
\end{tabular}


The specimens of $25 \times 25 \mathrm{~mm}$ cross section produced from the forged billets were rolled on a 210 rolling mill at a speed of $0.3 \mathrm{~m} / \mathrm{s}$ in $1-5$ passes one pass after heating in an electric furnace at $1150^{\circ} \mathrm{C}$ for $50 \mathrm{~min}$. The strain (reduction) in each pass $\varepsilon_{i}$ was $10 \%$. Immediately after rolling, the specimens were quenched in water with a temperature not exceeding $25^{\circ} \mathrm{C}$. The rolling force during deformation of each specimen was recorded. The rolling pressure, $p$ was calculated using the formula: $p=\mathrm{F} / \mathrm{S}$, in which $\mathrm{F}$ is the rolling force and $\mathrm{S}$ - the horizontal projection of the surface contact area.

\section{RESULTS AND DISCUSSION}

The measured parameters and the mechanical properties of the HTMP treated steels are shown in Table 2.

Table 2 Rolling force parameters and mechanical properties of steels after HTMP with different number of rolling passes

\begin{tabular}{|c|c|c|c|c|c|c|c|c|}
\hline Steel & $\mathbf{n}$ & $\mathrm{F}, \mathrm{kN}$ & $\mathrm{p}, \mathrm{MPa}$ & YS, MPa & $\mathrm{TS}, \mathrm{MPa}$ & A, \% & RA, \% & HV \\
\hline \multirow[t]{5}{*}{$0.04 \mathrm{C} 18 \mathrm{Cr} 9 \mathrm{NiTi}$} & 1 & 43.0 & 105.0 & 315 & 640 & 53.0 & 71.0 & 200 \\
\hline & 2 & 64.0 & 149.0 & 342 & 623 & 50 & 71.0 & - \\
\hline & 3 & 78.0 & 174.5 & 390 & 700 & 50.5 & 68.0 & 204 \\
\hline & 4 & 95.0 & 218.1 & 396 & 672 & 44.0 & 67.0 & - \\
\hline & 5 & 112.1 & 243.4 & 410 & 665 & 46.2 & 70.2 & 265 \\
\hline \multirow[t]{5}{*}{ 0.1C18Cr9NiTi } & 1 & 44.6 & 108.7 & 292 & 618 & 58.2 & 72.5 & 165 \\
\hline & 2 & 65.0 & 153.0 & 331 & 625 & 57.2 & 74.1 & - \\
\hline & 3 & 79.3 & 176.3 & 356 & 655 & 53.2 & 72.2 & 215 \\
\hline & 4 & 98.1 & 222.4 & 388 & 665 & 48.1 & 73.1 & - \\
\hline & 5 & 121.4 & 259.5 & 420 & 681 & 46.1 & 70.0 & 241 \\
\hline \multirow[t]{5}{*}{$0.15 \mathrm{C} 18 \mathrm{Cr} 9 \mathrm{NiTi}$} & 1 & 45.1 & 103.2 & 294 & 658 & 54.3 & 67.6 & 190 \\
\hline & 2 & 61.0 & 142.9 & 322 & 633 & 56.4 & 72.5 & - \\
\hline & 3 & 79.8 & 180.7 & 342 & 692 & 49.0 & 68.8 & 245 \\
\hline & 4 & 99.4 & 228.5 & 375 & 671 & 48.8 & 71.4 & - \\
\hline & 5 & 123.6 & 269.7 & 441.2 & 699 & 46.3 & 69.8 & 298 \\
\hline \multirow[t]{5}{*}{$0.2 \mathrm{C} 18 \mathrm{Cr} 9 \mathrm{NiTi}$} & 1 & 46.7 & 106.9 & 319 & 660 & 55.7 & 71.3 & 178 \\
\hline & 2 & 56.7 & 130.8 & 330 & 657 & 55.4 & 72.2 & - \\
\hline & 3 & 72.8 & 160.2 & 365 & 681 & 53.6 & 70.5 & 231 \\
\hline & 4 & 96.6 & 211.5 & 461 & 681 & 33.8 & 64.5 & - \\
\hline & 5 & 131 & 266.7 & 479 & 698 & 32.9 & 62.5 & 238 \\
\hline
\end{tabular}

For comparative assessment of the changes in rolling pressure $(p)$ and yield strength (YS) of the steels, the dependence of $p j / p_{x} Y S_{i} / Y S_{1}$ and $\left(p_{i+1}-p_{i}\right) / p_{i}$ on the number of passes was determined (Figures 1 and 2 ), in which $p_{1}$ is the rolling pressure in the first pass; $p_{1}$ is the rolling pressure in the $i-$ th pass; $Y S_{1}$, and $Y S_{i}$ the yield strength of the steel treated by HTMP with one pass and in i passes correspondingly. The tabulated data show that the increase in the force, $\mathrm{F}$ and the rolling pressure, $\mathrm{p}$ in each consecutive pass is quite significant; during rolling of $0,2 \mathrm{C} 18 \mathrm{Cr} 9 \mathrm{NiTi}$ steel, for example, the increase in rolling force in the second pass was $10 \mathrm{kN}$ or $17.6 \%$ and the rolling pressure increased by $22.5 \%$. To determine whether this increase was caused by spread during rolling in the first pass and the decrease in metal temperature (the pause between the first and second 
passes was $4.5 \mathrm{~s}$ ), the authors carried out check calculations using a known procedure which did not take the effects of work hardening into account $[3,4]$. The calculations indicated that the force in the second pass increased by about $6.2 \%$ and the rolling pressure by about $3 \%$, which was considerably below the experimentally determined values. It therefore follows that work hardening has a considerable influence.

\subsection{MICROSTRUCTURE EVOLUTION}

Metallographic and TEM analysis showed that the structure of all the steels tended to become progressively refined result in formation of fragmented substructure or recrystallized structure with an increasing number of reductions in rolling (Figures $\mathbf{3} \mathbf{a}, \mathbf{b}$ ).

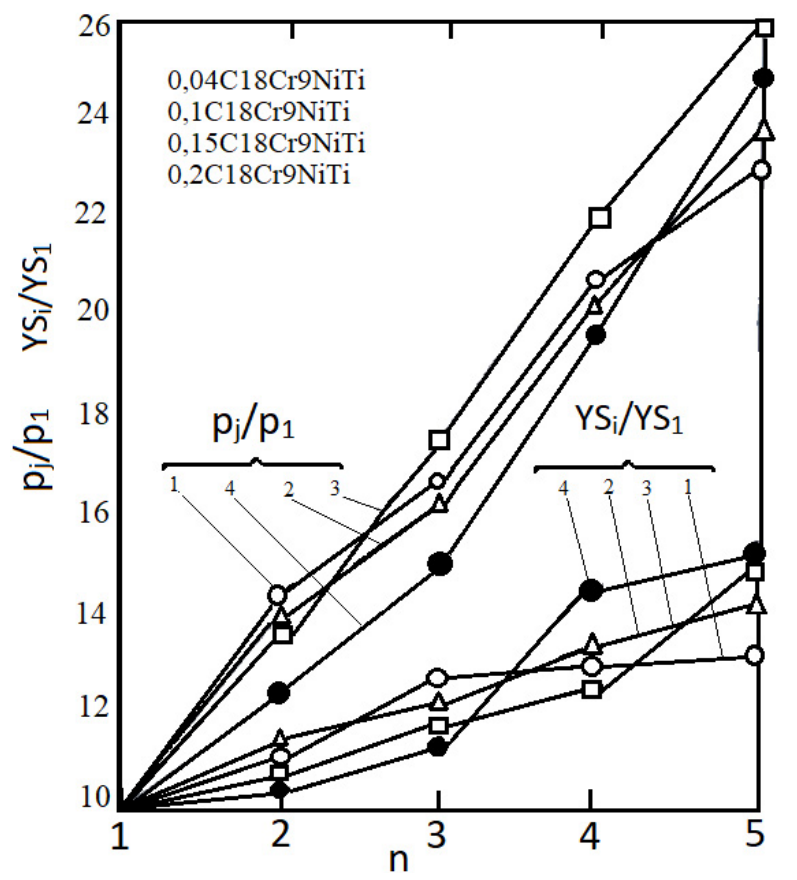

Figure 1 Rolling pressure ( $\left.\mathrm{pi} / \mathrm{p}_{1}\right)$ and yield strength $\left(\mathrm{YS}_{\mathrm{i}} / \mathrm{YS} \mathrm{S}_{1}\right)$ of Cr18-Ni9-Ti-type steels versus number of passes

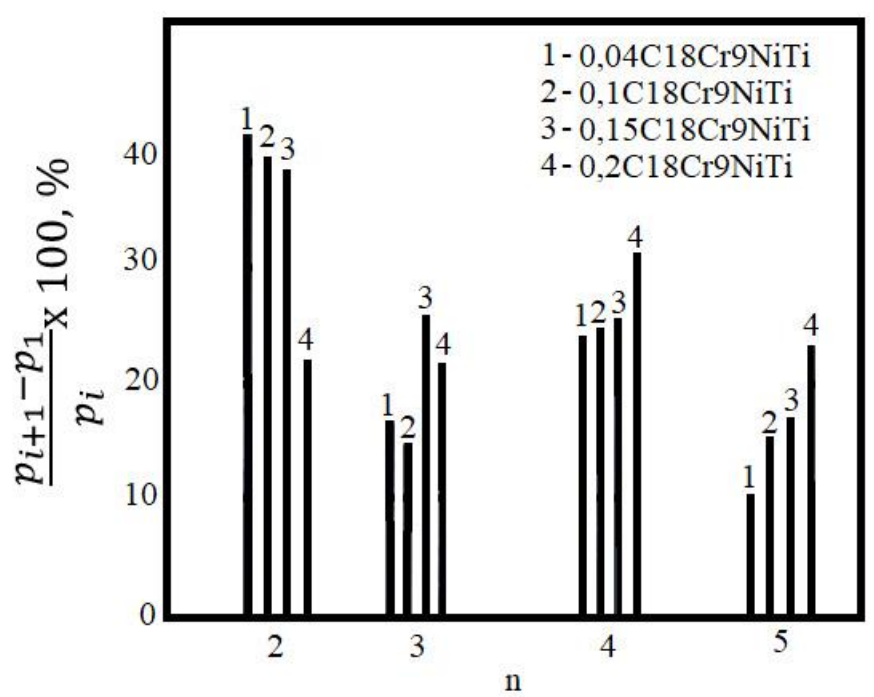

Figure 2 Increase in rolling pressure of Cr18-Ni9-Ti-type steels in each consecutive pass relative to preceding pass 


\subsubsection{Metallographic structure}

The microstructure in the initial state is characterized by large grains containing annealing twins and round carbide inclusions several microns across, distributed uniformly across the the volume in the all studied steels.

Under conditions of gradual multi-pass reduction, an increase in the total strain degree results in monotonic diminution of grain size $\bar{D}$ and growth of precipitate density. In addition, the length of the grains in the rolling direction growth noticeably as $\sum \varepsilon_{i}$ increases.

\subsubsection{Fine structure}

In the initial state $\left(50 \mathrm{~min}\right.$ at $1150^{\circ} \mathrm{C}$ followed by quenching) the dislocation density of the steel is low, at about $10^{8} \mathrm{~cm}^{-2}$. The boundaries are perfect and rectilinear, and do not contain precipitates. Coherent and incoherent boundaries of annealing twins are frequently encountered.

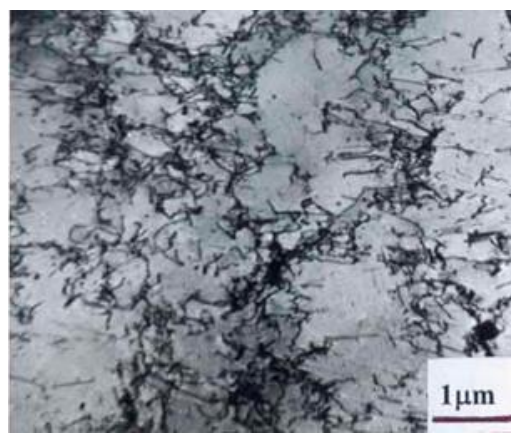

a

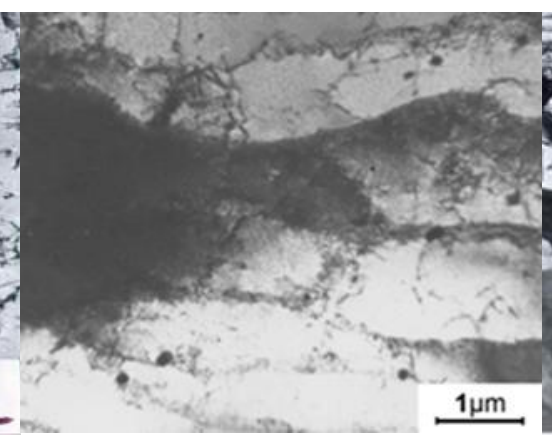

b

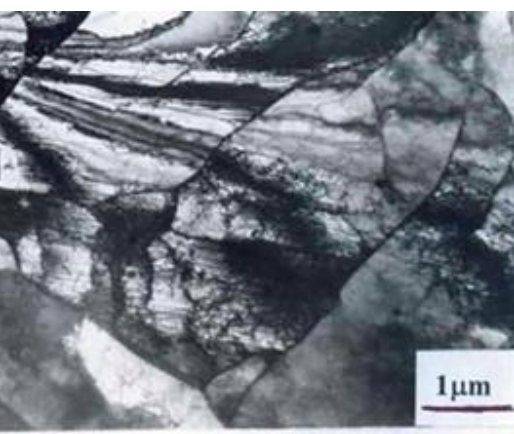

C

Figure 3 Structure (TEM) of 0,04C18Cr9NiTi steel deformed in various conditions: a) cellular dislocations structure in steel subjected to $10 \%$ one pass deformation; b) extended fragments in steel subjected to deformation in five (c) passes (10\% per one pass); c) fragments with carbide precipitates in steel subjected to deformation in five (c) passes (10\% per one pass)

Gradual multi-pass hot plastic deformation radically alters the initial structure of the steels. This is evidenced in the fact that the dislocation density increases, new misorientation boundaries of different forms arise, the structure of existing boundaries changes, and final-dispersed carbide precipitates appear (Figure 3c).

As the number of passes under multi-pass deformation increases, there is monotonic growth of dislocation density, $\rho$. It changes most, from $\sim 10^{8}$ to $\sim 1.5 \times 10^{10} \mathrm{~cm}^{-2}$, after the first pass. Subsequent deformation has only a slight influence on $\rho$. Increases to $2.0 \times 10^{10} \mathrm{~cm}^{-2}$ after three, and $2.3 \times 10^{10} \mathrm{~cm}^{-2}$ after five passes for the steel $0.04 \mathrm{C} 18 \mathrm{Cr} 9 \mathrm{NiTi}$. The spatial distribution of the dislocations also changes. As $\varepsilon=\sum \varepsilon_{i}$ grows, characteristic indications of dynamic recovery are more clearly seen in the dislocation structure. At first a weakly expressed cellular structure with not greater than $0.1{ }^{\circ} \mathrm{C}$ misorientation is formed (Figure 3a). Then individual boundaries elongated in the rolling direction, appear against that background, causing misorientations of about $\theta=1 \ldots 3^{\circ} \mathrm{C}$. The distances between them change from a few to tens of microns. The places where the boundaries break off, lines of partial disclinations [5,6] are sources of strong internal stresses. After rolling with $\varepsilon=10 \%$ such boundaries are found in all the grains. However, they form regions of fragmented structure in the most favorable oriented grains. The fragments are microregions of size $\sim 0.5 \mu \mathrm{m}$, enclosed on all sides by dislocation boundaries and misoriented relative to the surrounding matrix or neighbouring fragments by angles of $1 \ldots 3^{\circ} \mathrm{C}$. The volume fraction $\Delta^{f}$ occupied by a fragmented structure is only $5 \ldots 10 \%$ after the first pass. As the deformation accumulates, a larger and larger volume of material becomes fragmented. Thus, after the third pass $\Delta^{\dagger}$ reaches $60-70 \%$, after the fifth $-80-90 \%$. The fragmented structure becomes more perfect, the quantity of torn-off boundaries diminishes and their dislocation structure becomes ordered. The fragments become finer on average, the misorientation between them increasing appreciably. After one-pass reduction, 
the misorientation angles are $1 \ldots 3^{\circ}$. They increase sharply as a result of five-pass reduction, reaching several tens of degrees on individual boundaries, another peculiarity in the evolution of the fragmented structure is that the fragments grow progressively longer in the rolling direction (Figure $\mathbf{3 b}$ ). As for effect of carbon content it is important to follow the behavior of carbides during multipass deformation. The number of carbides precipitated during decomposition of the austenite increased from pass to pass result in hot deformation effect. With several reductions, moreover, there was a decrease in temperature which also promoted carbide precipitation. The quantity of carbide phase and the recrystallized grains fraction is increased with the carbon content. As shown in Figure 2, the work hardening which the steel underwent in the first pass was partly retained through to the second pass. In the third pass, the increase in rolling pressure was less than in the second pass. In the fourth pass, the rolling pressure increase was higher but in the fifth pass somewhat lower than in the preceding passes. The rolling pressure increased with the carbon content of the steel although the pressure increase from pass to pass was smaller. In the final passes, the rolling pressure increased more sharply as the carbon content increased. This type of change in rolling pressure results from two separate processes which influence the steel strength in different ways, namely softening due to recrystallization and strengthening due to carbide precipitation. The latter process accelerates and becomes more pronounced with an increasing number of passes and a simultaneous reduction in temperature. Carbon increases the diffusivity of iron atoms and with increasing carbon content, recrystallization processes are accelerated and softening takes place [7]. On the other hand, an increase in carbon content causes a rise in the number of carbides which have a retarding influence on recrystallization by blocking of the grain boundaries. The degree of softening retained and, consequently, the deformation resistance of the metal will vary according to the predominance of one or other of these mechanisms. With a rolling temperature of $1100-1150{ }^{\circ} \mathrm{C}$ in the first 3 passes, an increase in carbon content leads to acceleration of softening processes, while with a lower rolling temperature and a larger number of passes, the reverse effect is observed.

The kinetics of the change in rolling pressure with an increasing number of passes follow a similar pattern to the change in strength of the HTMP treated billet (Figure 1). The heightening in strength with an increasing number of passes can be correlated with the increase in residual strengthening. It can therefore be concluded that the effectiveness of HTMP is determined not by the strength level attained as a result of high-temperature deformation, but by the strength which is retained up to the moment of quenching, since the strengthening retained by the metal due to high-temperature deformation unavoidably decreases in the pauses between the passes and also between the end of rolling and the start of quenching. This is confirmed by high-temperature thermomechanical processing theory $[8,9]$.

\subsection{Mechanical properties}

To create the proper processing parameters for rolling with HTMP, it is worthwhile to compare the mechanical properties of steel rolled in $n$ passes with an overall strain (rolling reduction) $\sum_{i=1}^{n} e i$ with those of steel rolled in a single pass with $e k=\sum_{i=1}^{n} e i$. In the present study HTMP was carried out with rolling in a single pass (preceding parentheses) and 4 passes (in parentheses) with an overall reduction of $40 \%$. The finish rolling temperature in both cases was $1080^{\circ} \mathrm{C}$. The mechanical properties obtained were in Table 3:

Table 3 Mechanical properties of steels treated under HTMP with one and four passes

\begin{tabular}{|c|c|c|c|c|}
\hline Steel & YS, MPa & TS, MPa & A, \% & RA, \% \\
\hline $0.04 \mathrm{C} 18 \mathrm{Cr} 9 \mathrm{NiTi}$ & $311(397)$ & $637(673)$ & $48.7(43.8)$ & $73.2(67.1)$ \\
\hline $0.1 \mathrm{C} 18 \mathrm{Cr} 9 \mathrm{NiTi}$ & $269(389)$ & $618(666)$ & $55.2(48.3)$ & $74.1(73.2)$ \\
\hline $0.15 \mathrm{C} 18 \mathrm{Cr} 9 \mathrm{NiTi}$ & $244(375)$ & $679(670$ & $54.8(48.9)$ & $72.0(71.5)$ \\
\hline $0.2 \mathrm{C} 18 \mathrm{Cr} 9 \mathrm{NiTi}$ & $296(462)$ & $655(682)$ & $538(34.0)$ & $73.2(64.6)$ \\
\hline
\end{tabular}


The trials showed that an increase in the number of passes with a constant overall reduction led to a greater degree of strengthening of the steel. At the same time a decrease in carbon content led to retention of high ductile properties. The results of the above study were used to develop a practice for rolling $0,04 \mathrm{C} 18 \mathrm{Cr} 9 \mathrm{NiTi}$ steel with HTMP in a ten-stand 350 mill at the Petrosteel Industrial Co. Deformation in the last 5 stands was carried out on a multipass basis; stands $6,7,8,9$, and 10 formed a continuous group. The rolling force was calculated in two ways; by referring to the experimental data and by use of an earlier procedure [3] excluding consideration of the influence of work hardening $\left(n_{w h}=1\right)$. The rolling force in the first case proved to be $10-$ $40 \%$ higher than the values calculated with the normal procedure [3]. During rolling of $36 \mathrm{~mm}$ dia. rounds, moreover, the rolling force in the tenth stand was $555 \mathrm{kN}$ compared to the value of $415 \mathrm{kN}$ calculated using the standard procedure [3].

\section{CONCLUSIONS}

An increase in the number of passes during rolling of 18-10-type austenitic Cr-Ni-Ti stainless steel with different carbon contents steels has a beneficial effect on the tensile properties attained while preserving adequate ductile properties. With a rolling temperature of $1100-1150^{\circ} \mathrm{C}$ and rolling in 1-3 passes, an increase in carbon content leads to acceleration of softening processes; with lower rolling temperature and an increase in the number of passes, the reverse effect is observed. When developing a practice for multi-pass rolling, particularly with application of HTMP involving cooling before the final passes, it is necessary to take residual strengthening into account when calculating the rolling force. A reduction in the finish-rolling temperature with the aim of increasing the degree of hardening of the stock without allowing for residual strengthening can lead to breakage of the rolls.

\section{REFERENCES}

[1] LEVIT V. I., SMIRNOV M. A. High Temperature Thermomechanical Processing of austenitic steels and alloys. Cheliabinsk, 1995, p. 258.

[2] BERNSHTEIN M.L., DOBATKIN S.V., KAPUTKINA L.M., PROKOSHKIN S.D., Hot deformation diagrams, structure and properties. Moscow: Metallurgia, 1989, p. 544.

[3] SMIRNOV, V.S. "Theory of rolling" (Teoriya prokatki). Moscow: Metallurgia, 1967, p. 460.

[4] HOSFORD W. F., CADDELL R. M., Metal Forming Metallic and Metallurgy, 2011, p. 344.

[5] RYBIN V. V. The large plastic deformations and destruction of metals. Moscow: Metallurgia. 1987.

[6] KODZHASPIROV G. E., RUDSKOI A. I., RYBIN V. V. Physical fundamentals and resourse saving technologies of the articles production by metal forming. St.Petersburg, 2007, p. 350.

[7] GRUZIN P. L. et al. 'Problems in metal science and metal physics' (Problemy metallovedeniya i fiziki metallov). Moscow: Metallurgizdat, 1952, pp. 225-236.

[8] BERNSHTEIN M. L., ZAIMOVSKII V. A., KAPUTKINA L. M. Thermomechanical processing of steels. Moscow: Metallurgia, 1983, p. 480.

[9] KODJASPIROV (KODZHASPIROV) G.E., KIM I. Thermomechanical Processing of steels. St.Petersburg, 1998, p. 228. 